\title{
Proposing a mobile blood appeal system for Nigeria
}

\author{
Uzor Tochukwu Valentine $^{1 *}$, Sellappan Palaniappan ${ }^{1}$ and Datukun Kalamba A. ${ }^{2}$ \\ Malaysia University of Science and Technology, Selangor, Malaysia ${ }^{1}$ \\ Plateau State University Bokkos, Nigeria ${ }^{2}$
}

\section{(C2016 ACCENTS}

\begin{abstract}
It has been a common practice for blood donors to donate blood in a tradition way of physical contact with the experts in Nigeria. Is either donors physically go to the hospital at will to request to donate blood and then screened if accepted or take advantage of physical donation campaign to further do so. This has been boring trying to go through such process and has only been taking a few volunteers going through such. Nigeria has been faced with a lot of prolonged process in trying to get blood donated, usually manual, which has been affecting patients needing blood urgently. Working on a mobile system that makes it easier for donors to book and donate blood at any time for intending blood acceptors, is important. This paper seeks to analyze the manual system of blood donation in Nigeria, against the development of the mobile system. We will be analyzing the primary data, being the initial process for the development of the mobile system, present the system requirements, research flowchart and application flowchart. This will coincidentally take us to the full development of the mobile system in our later work.
\end{abstract}

\section{Keywords}

Blood donors. Mobile appeal svstem. Blood acceptors. Application flowchart.

\section{Introduction}

Blood donation can be classified under the medical supply transportation problem as a healthcare logistic problems [1]. Blood transfusion is a safe, common procedure in which blood is given to you through intravenous (IV) line in one of your blood vessel. In 1898 , it was discovered that inherited differences in people's red blood cell were the cause of the many incompatibilities with transfusion. Karl Landsteiner then discovered the three blood typing.

In human body, blood donation have remain the only source of getting blood for transfusion. Blood transfusion service (BTS), blood safety paramount and the only safe blood is often referred to those non -remunerated blood (WHO, IFBDO). Blood is often required in emergency situation like accident victims, surgery, cancer patients, and sickle cell anaemia patients. Available blood in human system is 4.7 litres to 5 litres of blood.

*Author for correspondence

\section{Literature review}

It is important to evaluate how well the data meet the quality requirements of the current research and the methodological criteria of good scientific practice [2]. Primary data [3] would enhance the intending evaluation process. It is necessary for the researcher to know not only the research methods/techniques but also the methodology [4].

The study as combination of both inductive and deductive has been addressed [5]. As a result of the identification, exploration and experimentation of the current literature related to mobile blood appeal system and its application.

Blood transfusion is not only a problem in Nigeria but also in developed nations, according to American red cross indicates that every two second someone in America requires blood transfusion and more than 41000 blood donation are needed every day [6]. describe blood donation as the only way to acquire blood to meet emergency need .Donated blood can be a lifesaving for individuals who have lost large volumes of blood from serious accident, obstetric and gynecological hemorrhage or surgical and stem transplant patients as well as for individuals who have symptomatic anemia from medical or hematological conditions or cancers $[7,8]$. If $10 \%$ of 
Nigerians populace donate blood regularly, then there will be minimal blood shortage. Donor recruitment has been a great source of getting blood for patients. Blood donors can either be classified as voluntary donor, family replacement donor and paid or remunerated donors.

Nigeria over the years have strived to establish national blood transfusion service (NBTS) which dated back to early 1960's. At Nigeria current level of healthcare delivery, it is estimated that about 1.5 million unit of blood will be required annually. However, a national baseline data survey on blood transfusion in August 2005 indicates that only about half a million unit of blood were collected from private and public sources in the previous one year with paid donor accounting for more than $90 \%$ of the donated blood. Paid donor are argued to be associated with high risk of transfusion-transmissible infection including HIV, Hepatitis C and Syphilis [9]. An estimated $3.2 \%$ of Nigeria populations are living with HIV/AIDS, it is estimated that 3.4 million out of more than 180 million are living with the virus. HIV transmitted through unsafe blood accounts for the second largest source of HIV infection in Nigeria according to UNAIDS, in 2014.

UML is one of the major purpose is to provide the development community with a stable and common design language that can could be used to develop and build computer application [10].

\section{Methods}

As a method followed to obtain relevant data for this work, questionnaire was adopted for both blood donors, acceptors and transfusion experts. Age, marital status, occupation and nationality was considered for the demography collection of data, ascertaining the usefulness of blood donation and if mobile system would enhance the process, particularly in Nigeria. Next, we prepare the necessary requirements for the intending mobile system.

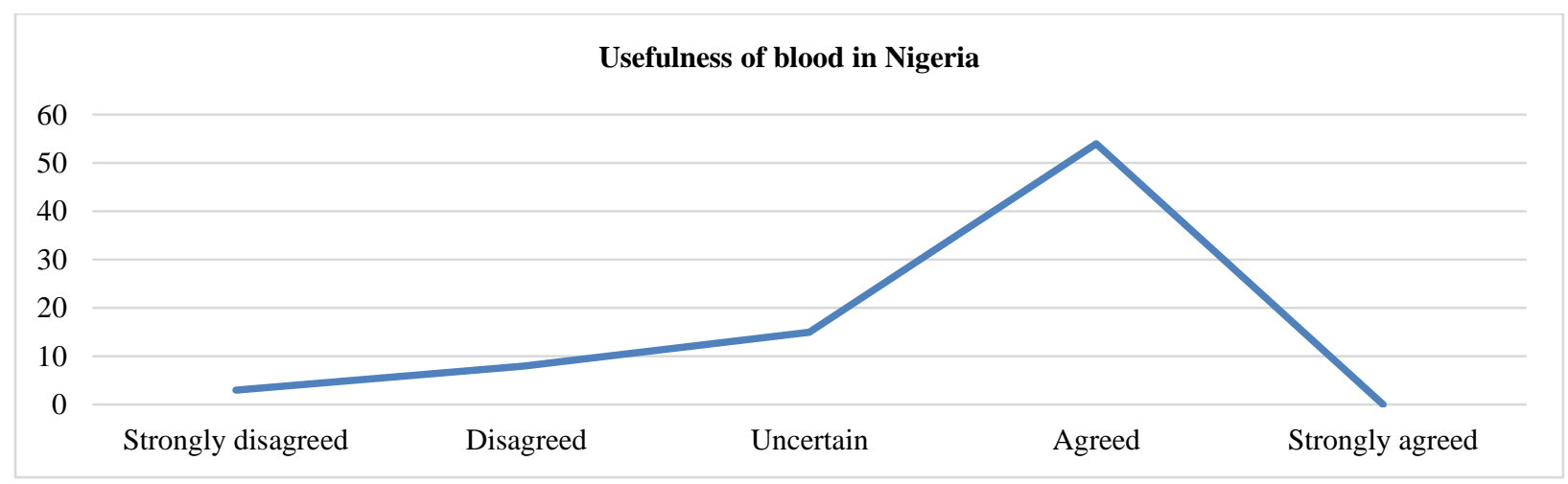

Figure 1 Respondents' view on the mobile appeals

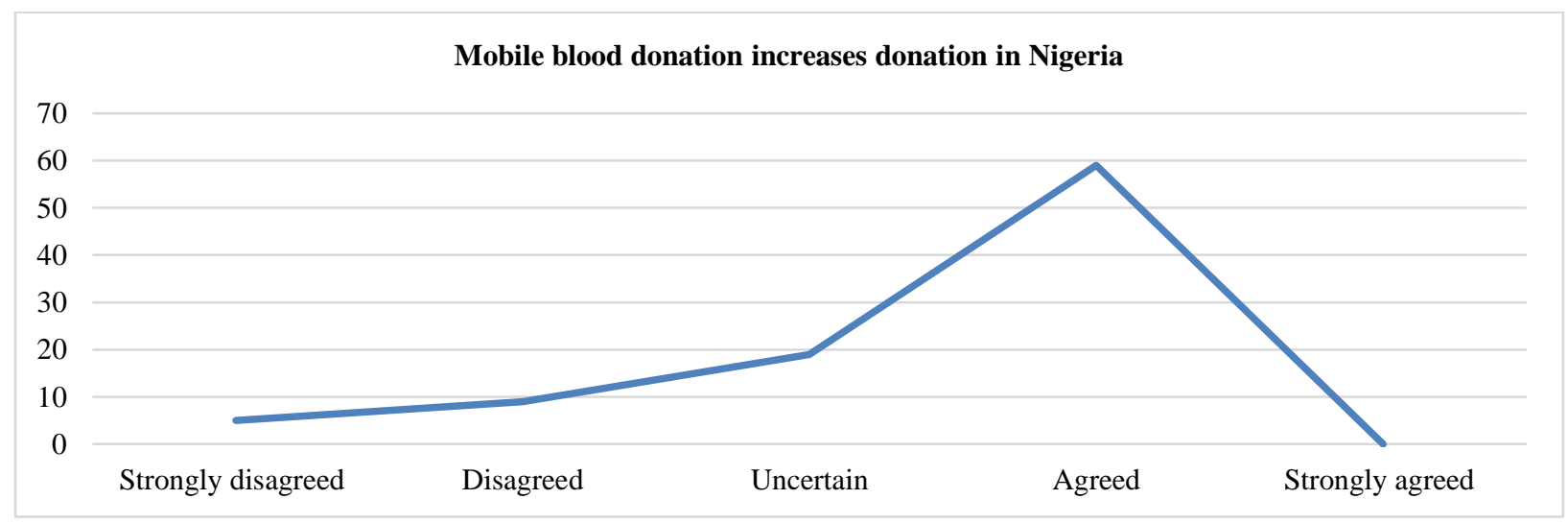

Figure 2 Respondents' view on the mobile appeal system 


\section{Results}

The results of questionnaire administered to

included in this section plus flowchart that describes concerned respondents are tabulated and charts plotted. Tables of system requirements are also

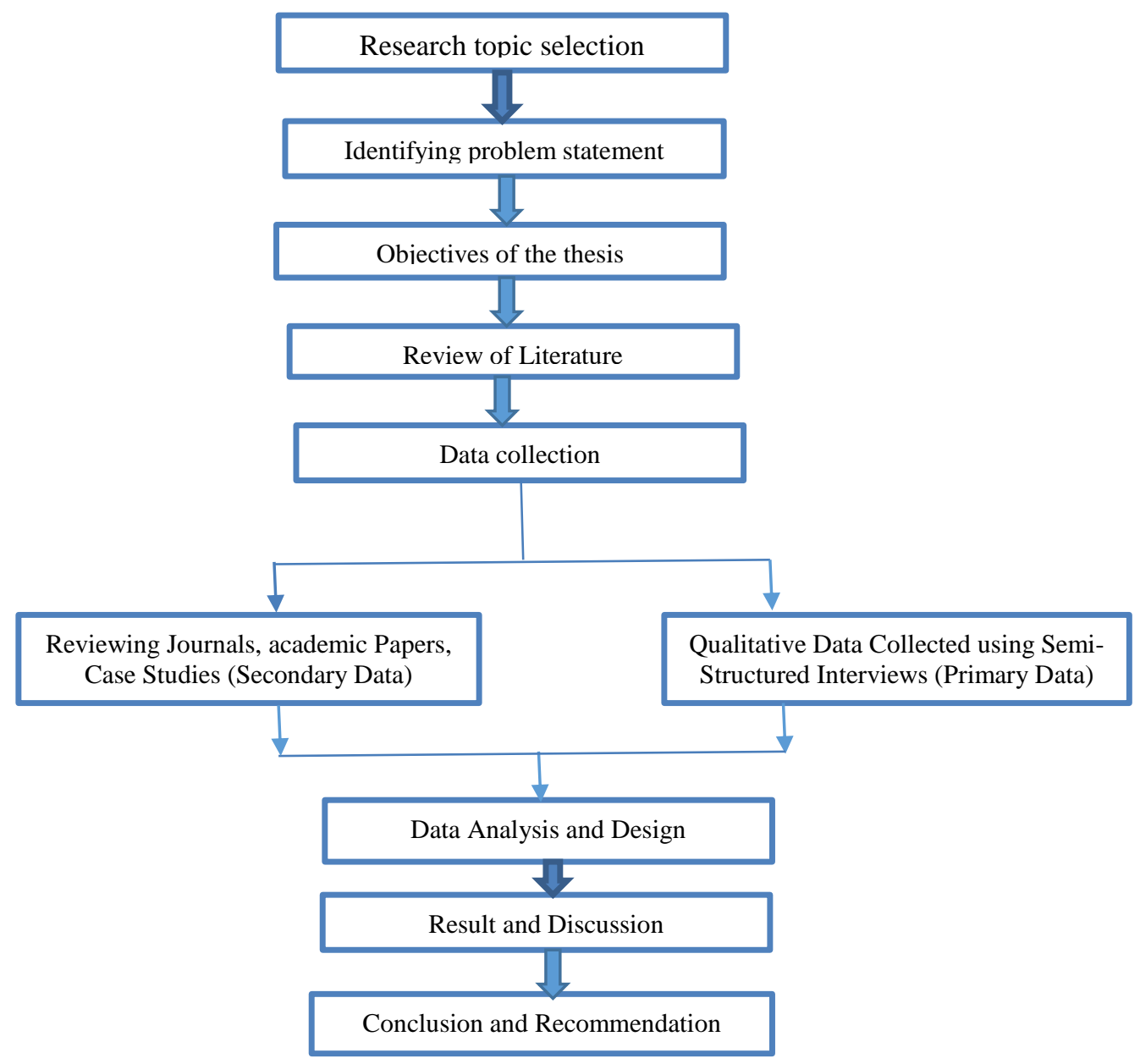

Figure 3 Research flow chart

\section{Discussion}

From Table 1 and Figure 1 , we will see that the opinions of the respondents on the usefulness of blood donation in Nigeria. The table and chart explains that 3 people strongly disagree, 8 disagree, 15 uncertain, 54 agreed and none strongly disagree. This is to say that majority agrees that the blood donation system is useful. Table 2 and Figure 2 shows that 5 strongly disagree, 9 disagree, 19 uncertain, 59 agree and none strongly disagree that mobile system would enhance the blood donation and accepting system. It entails that majority agrees that the mobile blood donation system will be useful. Table 3 simply describes us the basic requirements for the development of the mobile blood donation appeal system. Figure 3 give detailed explanation on how the system will be developed from the from the research topic to the conclusion. The research flow chart gives stages in which the problem statement is achieved and identified, how the specific objectives will be carried out in the system development.

Figure 4 describes the application flowchart; how the application is being developed, explaining the various modules of the application covering the scope of this paper. However, we will proceed with the case diagram against the full application development as our subsequent work. 
Uzor Tochukwu Valentine et al.

Table1 Blood donation usefulness in Nigeria

\begin{tabular}{lllll}
\hline $\begin{array}{l}\text { Strongly } \\
\text { Disagreed }\end{array}$ & Disagreed & Uncertain & Agreed & $\begin{array}{l}\text { Strongly } \\
\text { Agreed }\end{array}$ \\
\hline 3 & 8 & 15 & 54 & 0 \\
\hline
\end{tabular}

Table 2 Respondents' view on the mobile appeal system

\begin{tabular}{lllll}
\hline $\begin{array}{l}\text { Strongly } \\
\text { disagreed }\end{array}$ & Disagreed & Uncertain & Agreed & $\begin{array}{l}\text { Strongly } \\
\text { disagreed }\end{array}$ \\
\hline 5 & 9 & 19 & 59 & 0 \\
\hline
\end{tabular}

Table 3 Basic system requirements

\begin{tabular}{ll}
\hline Purpose & Software \\
\hline Database & SQLite 3.13.0 \\
Designing of UML Diagram & MS Visio 2013 \\
Designing of system flow chart & MS Visio 2013 \\
Coding of the Source code & Eclipse IDE 9.0 \\
\hline
\end{tabular}

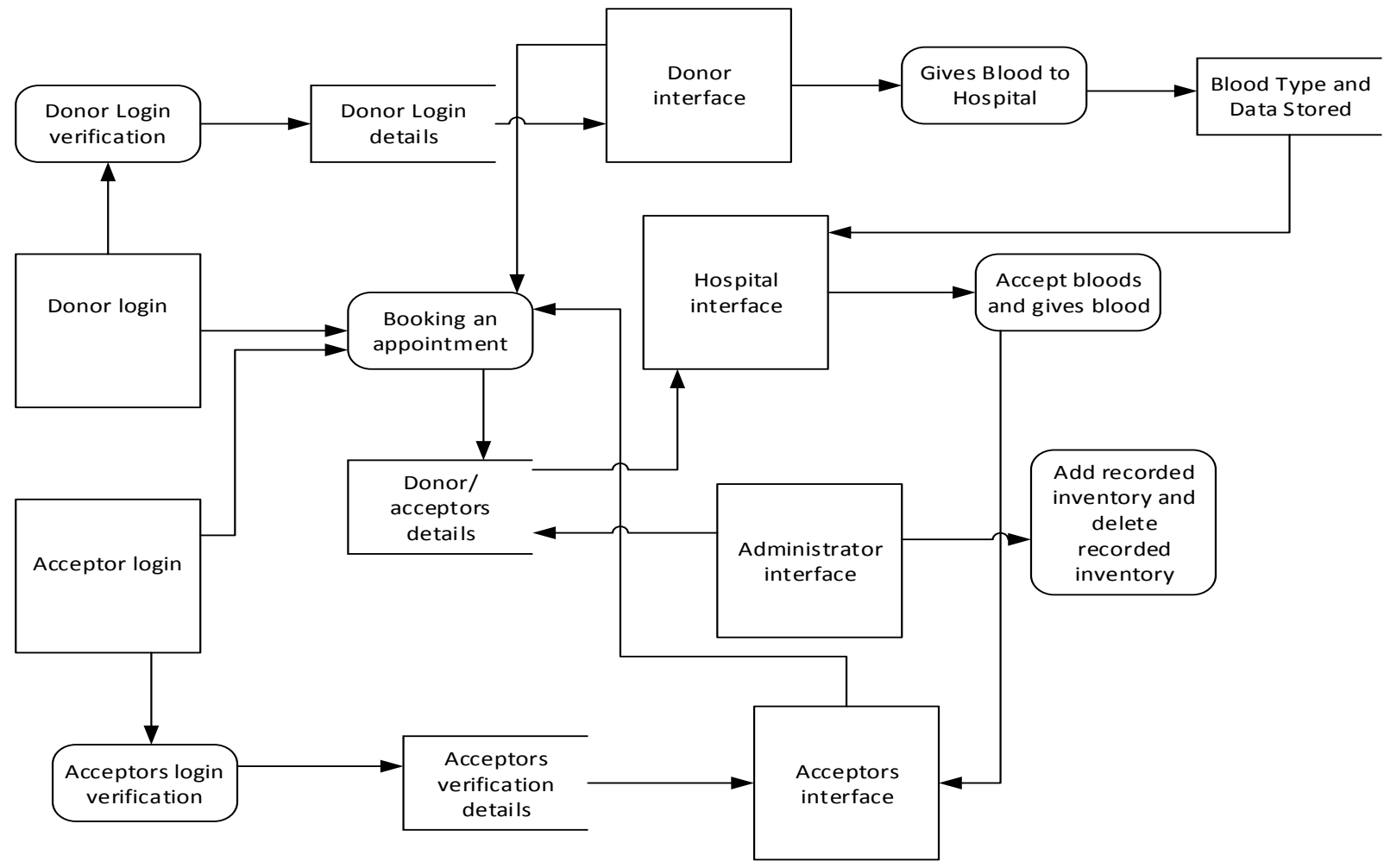

Figure 4 Application flow chart

\section{Conclusion}

From the requirements analysis, we had confident to proceed with mobile system of blood donation and accepting. It has been established that the intending system will boost the blood donation and accepting process in Nigeria. It will further helps in reduction of death rate and give easy accessibility to the Nigeria populace in an emergency situation whereby donors location and contacts are already know to appeal to whenever in need.

Acknowledgment

As the main author of this paper, I thank all respondents that makes this research a reality. Also, I thank my parents for encouragement in different ways. More so, I appreciate Prof. Dr. Sellappan for 
his academic contribution and immense guidance in this paper development.

\section{Conflicts of interest}

The authors have no conflicts of interest to declare.

\section{References}

[1] Acton QA. Hormones: advances in research and applications. Scholarly Editions; 2012.

[2] Hox JJ, Boeije HR. Data collection, primary vs. secondary. Encyclopedia of social measurement. 2005:593-9.

[3] Currie D. Collecting Primary Data. CIPD Publishing; 2005.

[4] Kothari CR. Research methodology: methods and techniques. New Age International; 2004.

[5] Saunders WM, Goldenberg CN, Gallimore R. Increasing achievement by focusing grade-level teams on improving classroom learning: A prospective, quasi-experimental study of Title I schools. American Educational Research Journal. 2009; 46(4):1006-33.
[6] Salaudeen AG, Odeh E. Knowledge and behavior towards voluntary blood donation among students of a tertiary institution in Nigeria. Nigerian Journal of Clinical Practice. 2011; 14(3):303-7.

[7] Nwogoh B, Aigberadion U, Nwannadi AI. Knowledge, attitude, and practice of voluntary blood donation among healthcare workers at the University of Benin Teaching Hospital, Benin City, Nigeria. Journal of Blood Transfusion. 2013.

[8] Benedict N, Usimenahon A, Alexander NI, Isi A. Knowledge, attitude and practice of voluntary blood donation among physicians in a tertiary health facility of a developing country. Journal of Blood Disorders \& Transfusion. 2012.

[9] Mascaretti L, James V, Barbara J, Cárdenas JM, Blagoevska M, Haračić M, et al. Comparative analysis of national regulations concerning blood safety across Europe. Transfusion Medicine. 2004; 14(2):105-12.

[10] Bell D. UML basics Part II: The activity diagram. IBM Global Services, Rational Software. 2003. 